\title{
Simulating the impact of landscape-level biodiversity guidelines: A case study
}

\author{
by David W. Andison ${ }^{1}$ and Peter L. Marshall ${ }^{2}$
}

British Columbia, along with most of the rest of North America, is becoming preoccupied with emulating natural landscape patterns under the auspices of ecosystem management. With their Biodiversity Guidebook, BC developed one of the first collections of rules for landscape management purposes. The landscape-level rules developed therein are representative of those being developed in other areas of North America. This research compared, in simulation, a range of patterns created by these guidelines for a landscape in central BC, against those created from the historical 60 hectare two-pass system, and a "natural" disturbance regime. Results indicate that the biodiversity guidelines created more natural levels of patch sizes, interior forest area, and seral guidelines failed to create more natural rates of disturbance, or ranges of patch sizes and interior areas in old and mature forest. Furthermore, the implied degree of naturalness of the low, medium, and high biodiversity options did not necessarily hold true. The simulation results presented in this paper show that the concept of mimicry involves much more than originally had been supposed, and that there are limits to the degree to which mimicry can be used as a landscape management paradigm with our current knowledge and ability. A strategy for working towards a natural landscape pattern program for forest management is discussed.

Key words: landscape level, biodiversity, simulation, disturbance stage percentages compared to the two-pass system. However, the

La Colombie-Britannique, comme la majeure partie de l'Amérique du Nord, est de plus en plus préoccupée par la simulation des patrons naturels des paysages pour suivre les préceptes de l'aménagement écosystémique. Avec son guide de biodiversité, la province a élaboré l'une des premières collections de règles dans le cadre de l'aménagement des paysages. Les règles au niveau des paysages décrites ci-après, sont représentatives de celles qui sont en voie d'élaboration dans d'autres régions de l'Amérique du Nord. Cette recherche a comparé, lors de simulation, différents patrons créés par ces lignes directrices pour les paysages du centre de la province, par rapport à ceux créés selon le système habituel de deux interventions sur 60 hectares, et un régime de perturbation "naturelle." Les résultats démontrent que les lignes directrices de biodiversité ont créé un niveau plus naturel en ce qui a trait aux dimensions des interventions, au domaine de forêt intérieure, et aux pourcentages des séries comparativement au système à deux interventions. Toutefois, les lignes directrices n'ont pas permettre de créer des taux plus naturels de perturbation, ou d'étendues des superficies traitées et des superficies intérieures des vieilles forêts et des forêts matures. De plus, le degré sous-entendu d'aspect naturel des options de biodiversité de bas, moyen et haut niveau n'a pas nécessairement été maintenu. Les résultats de cette simulation présentés dans cet exposé indiquent que le concept d'imitation comprend beaucoup plus d'aspect que supposés à l'origine, et qu'il y a des limites en ce qui concerne le niveau d'imitation qui peut être utilisé en tant que paradigme d'aménagement des paysages selon nos connaissances et nos capacités actuelles. Une stratégie pour élaborer un programme de patron naturel d'aménagement des paysages en aménagement forestier est discutée.

Mots-cles: niveau du paysage, biodiversité, simulation, perterbation

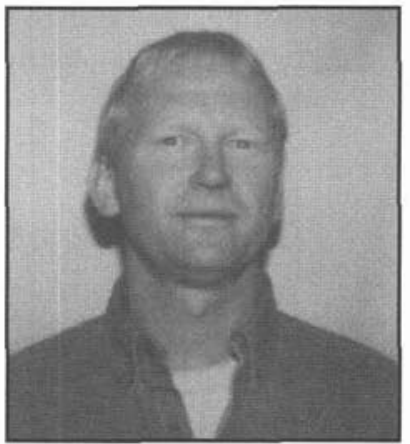

D.W. Andison

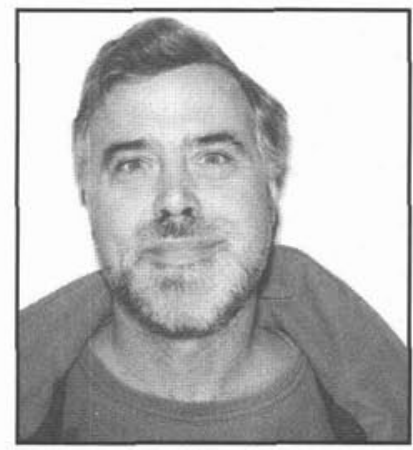

P.L. Marshall itate the transition to landscape-level forest planning, the BC government initiated eight pilot projects. Seven of these involved developing comprehensive landscape plans. The eighth pilot project, for the Prince George Forest District of the BC Ministry of Forests $(\mathrm{MoF})$, involved investigating the success of the biodiversity guidelines relative to their stated goal of approximating natural disturbance processes.

The Prince George Forest District is in an enviable position to implement landscape-level guidelines. The District is

\footnotetext{
${ }^{1}$ Owner/Operator, Bandaloop Landscape-Ecosystem Services, 30 Debra Ann Rd., Golden, CO, USA 80403.

${ }^{2}$ Associate Professor, Forest Resources Management Dept., University of British Columbia, 270-2357 Main Mall, Vancouver, B.C., Canada. V6T 1 Z4.
}

largely comprised of relatively simple forest-types, characterized by stand-replacing disturbance regimes. In addition, recent work by DeLong and Tanner (1996) and Andison (1996) have produced details on the disturbance regimes. These circumstances allow a more rigorous landscape unit pilot project involving computer simulation to determine the potential impacts of various management options on the landscape through time. Our objective in this paper is to present the results and interpretations of those simulations, and to determine the relative success of the guidelines in terms of natural disturbance pattern "mimicry" at landscape scales. 
Table 1. Summary of Natural Disturbance Type 3 (NDT3) conditions as laid out in the Biodiversity Guidebook (BC Ministry of Forests and BC Environment 1995).

\begin{tabular}{|c|c|c|c|c|}
\hline \multirow[b]{2}{*}{ Attributes } & \multirow{2}{*}{$\begin{array}{l}\text { Seral Stage Recommendations } \\
\text { Biodiversity Emphasis }\end{array}$} & \multicolumn{3}{|c|}{ Seral Stage } \\
\hline & & Young & Mature + Old & Old \\
\hline Age Range (years) & & $\leq 40$ & $\geq 100$ & $\geq 140$ \\
\hline \multirow[t]{5}{*}{ Area Distribution (\%) } & Low & - & $\geq 11$ & $\geq 11$ \\
\hline & Intermediate & $\leq 54$ & $\geq 23$ & $\geq 11$ \\
\hline & High & $\leq 40$ & $\geq 34$ & $\geq 16$ \\
\hline & Patch Size Recommendations & & tch Size (hectar & \\
\hline & & $\leq 40$ & $41-249$ & $250-1000$ \\
\hline Recommended Distribution by Area (\%) & & $10-20$ & $10-20$ & $60-80$ \\
\hline
\end{tabular}

More generally, the subject of natural pattern mimicry is receiving a great deal of attention throughout the world, and for the most part sweeping statements and assumptions are being made about the degree to which it can be accomplished. At the very least, this study represents a first look at how so-called ecologically-based management guidelines might be achieving the desired objectives.

\section{Study Area}

The Prince George Forest District, like other forest districts in BC, has divided its land base into "landscape units" based on large-scale physiographic features. Forty-seven landscape units between 60000 and 131000 hectares were delineated for this area of the Province. The Peculiar-Merton landscape unit (130845 ha), located immediately north of Prince George on the Nechako Plateau, was chosen for the pilot project because it represents ecological and management conditions typical of the area.

All but 706 hectares of the Peculiar-Merton landscape unit fall within the Mossvale Moist Cool Sub-Boreal Spruce variant (SBSmk1) of the BC Biogeoclimatic Ecosystem Classification (BEC) system. The SBSmk1 covers almost 800000 hectares in central British Columbia. The climate of the SBSmk1 is typically continental (long winters and moist cool summers), and varies little across its geographic extent. Soils are Grey Luvisols to Podzols, and the topography gently rolling (DeLong et al. 1993). Principle tree species are lodgepole pine (Pinus contorta) and hybrid interior spruce (Picea glauca $\times$ engelmannii), with minor components of black spruce (Picea mariana), trembling aspen (Populus tremuloides), black cottonwood (Populus trichocarpa), subalpine fir (Abies lasiocarpa) and Douglas-fir (Pseudotsuga menziesii).

Forest fires, bark beetle (Dendroctonus spp.) and windthrow are the dominant disturbances in the SBSmk1, although fires are often associated with the other two events (Andison 1996). The average fire cycle has been estimated to be approximately 93 years (Andison 1996), and most fires here lead to high mortality, and even-aged stands (Johnson 1992). It is assumed that arboreal succession is not a significant landscape factor in this area because of the short period between fires, and the susceptibility of the dominant species to fire (Johnson 1992, Payette 1993). Existing stand composition is largely a function of the severity of the initiating fire, the age and composition of the previous stand, and species strategies and preferences (Parminter 1983).

The SBSmk1 falls within a natural disturbance type characterized as having "frequent stand-initiating events" (BC Ministry of Forests and BC Environment 1995. The recom-
Table 2. Summary of the Peculiar-Merton Landscape Unit.

\begin{tabular}{lc}
\hline \multicolumn{2}{c}{ Forest Land base } \\
\hline Category & Area (ha) \\
\hline Total Area & 130845 \\
Private Land & -17773 \\
Water & -8934 \\
Non-forested Land & -6960 \\
\hline Forested Crown Lands & 97178
\end{tabular}

Reductions to Forested Crown Lands

\begin{tabular}{lr}
\hline Category & Area (ha) \\
\hline Environmentally Sensitive Areas & -607 \\
Low Productivity Areas & -3975 \\
Areas with Non-Commercial Species & -6910 \\
Inoperable Areas & -5210 \\
Roads (estimate) & -2247 \\
\hline Timber Land Base for Analyses & 78229 \\
\hline
\end{tabular}

Table 3. Area occupied by stands categorized by dominant species groupings in the crown forest land base of the Peculiar-Merton Landscape Unit.

\begin{tabular}{lrc}
\hline Dominant Species & Area (ha) & $\begin{array}{c}\text { Percent of } \\
\text { Total Area }\end{array}$ \\
\hline Lodgepole pine & 37166 & 38 \\
Hybrid interior spruce & 19460 & 20 \\
Black spruce & 705 & 1 \\
Poplar spp. & 7048 & 7 \\
Softwood & 21209 & 22 \\
Mixedwood & 11590 & 12 \\
\hline Total & 97178 & 100 \\
\hline
\end{tabular}

mended landscape targets for seral stage and size-class distribution for this area of the SBSmk1 are outlined in Table 1 for three levels of biodiversity emphasis according to the guidelines: low, medium, and high. In addition to these targets, the Guidebook specifies that a minimum of $25 \%$ of the "old" seral stage occur in patches at least 40 hectares in size (BC Ministry of Forests and BC Environment 1995).

The bulk of the Peculiar-Merton landscape unit is composed of forested crown land (Table 2). Only this portion of the land base will be considered in the analyses that follow. Lodgepole pine stands dominate the landscape ( $38 \%$ - Table 3$)$, but are considerably less dominant than just to the north where these stands comprise $60 \%$ to $70 \%$ of the landscape. The amount of cultural activity, (mostly agriculture), in the southern portion of the landscape (close to the city of Prince George) has almost certainly increased the proportion of the area dominated 
Table 4. Forested area by age-class and seral stage.

\begin{tabular}{|c|c|c|c|c|c|c|}
\hline \multicolumn{3}{|c|}{ Age-Class Distribution } & \multicolumn{4}{|c|}{ Seral-Class Distribution } \\
\hline $\begin{array}{l}\text { Age-Class } \\
\text { (Years) }\end{array}$ & $\begin{array}{l}\text { Area } \\
(\mathbf{H a})\end{array}$ & Percent & Seral-Class & $\begin{array}{c}\text { Age Range } \\
\text { (Years) }\end{array}$ & $\begin{array}{l}\text { Area } \\
\text { (Ha) }\end{array}$ & Percent \\
\hline $0-20$ & 21661 & 22 & Early & $0-40$ & 24348 & 25 \\
\hline $21-40$ & 2687 & 3 & Pole & $41-100$ & 28013 & 29 \\
\hline $41-60$ & 7363 & 8 & Mature & $101-140$ & 22380 & 23 \\
\hline $61-80$ & 16361 & 17 & Old & $141+$ & 22437 & 23 \\
\hline $81-100$ & 4289 & 4 & & & & \\
\hline $101-120$ & 4450 & 5 & & & & \\
\hline $121-140$ & 17930 & 18 & & & & \\
\hline $141+$ & 22437 & 23 & & & & \\
\hline
\end{tabular}

by hardwood and mixed stands. Hybrid interior spruce comprises the second most prevalent single-species stands, covering $20 \%$ of the area.

The current age-class distribution was estimated using the most current digital inventory (Table 4). Harvesting and subsequent regeneration have created a large portion of the area less than 20 years of age (22\%). A significant portion of the landscape is also older than 140 years $(23 \%)$. These numbers are fairly typical of SBSmk1 landscapes. Since the purpose of the study was to determine the likely changes over time that might result from the Biodiversity Guidelines on the existing landscape, no effort was made to eliminate these harvested areas, or choose a land base with no harvesting. When the ages are classified according to seral stage (BC Ministry of Forests and BC Environment 1995), the breakdown is relatively even, emphasizing the large amount of old and mature forest.

\section{Methods}

\section{Simulating Landscape Patterns}

The objective of the simulation exercise was to develop multiple "possible" landscape scenes based on projections of information on the natural disturbance regime, compared to the landscape harvesting rules suggested in BC's Biodiversity Guidebook. To accomplish this, the model must 1) be stochastic, 2) be able to incorporate actual data on disturbance sizes, shapes, and frequencies, and 3) allow the measurement of pattern. Many excellent landscape disturbance models were available, and most notably LANDIS (Mladenoff et al. 1993) and DISPATCH (Baker et al. 1991) came close to satisfying these requirements. However, neither model at the time of this study was capable of being calibrated to different patch shapes. This ability was considered to be crucial to the robustness of the output.

Alternatively, Andison (1996) had created a suitable landscape computer model (LANDMINE) that was already calibrated for the SBSmk1 landscape. LANDMINE is based on the original cellular automaton formulation of Clarke et al. (1994), and uses standard digital pixel data from a wide range of sources. Disturbances spread from an ignition point based on "scores" of neighbouring pixels. These scores are determined from any number or type of spatial data overlays (Andison 1996, Clarke et al. 1994). Data used for this exercise included fueltypes, and slope percent and direction (uphill versus downhill). Scores were determined using rules from the Canadian Forest Fire Behaviour Prediction System (Taylor and Pike 1995) applied to standard inventory data and a digital terrain model. A fire will thus be more likely to go uphill, or towards older conifer stands, than downhill or into young hardwood forest.
The stochastic nature of the spread algorithm means that any disturbance started in the same place twice will always be different, although generally, disturbance spread will always have the same tendencies. Note that this does not make LANDMINE a fire behaviour model per se, designed to represent individual fire growth accurately. Rather, it represents average fire patterns over many years.

The disturbance growth module is used within a larger modelling framework that chooses disturbance sizes, also stochastically. A function defining the patch size distribution of the study area is shown in Fig. 1, along with the raw data. Only data from the very youngest patches were used for this, since older patches have a greater chance of being overlain by younger disturbances. Disturbance size is chosen in the model using the function through a random number generator. When the designated disturbance size is reached, the spread module simply stops.

The final layer of the LANDMINE model is a function that chooses a disturbance frequency. As with the disturbance size data, this is defined using empirical data, reconstructed from the age-class distribution (Fig. 2). The model runs in 20year time-steps, so the random number generator in this instance produces a 20 -year rate of disturbance, which in this case ranges from $7 \%$ to over $50 \%$ of the total area (Fig. 2). Thus, LANDMINE can be used to create a time-series of landscape snapshot mosaics in 20-year time steps by controlling fire sizes and frequencies, and responding to topographic or fuel-type changes.

One of the more powerful traits of the Clarke et al. (1994) spread formulation is the ability to calibrate patch shape, as well as numbers and sizes of remnant islands. This attribute was considered crucial to the legitimacy of the model output. Previous to this study, Andison (1996) calibrated the spread movement such that disturbance shapes matched those observed, and also matched the model output of the numbers and sizes of unburnt islands in each disturbance to those reported by DeLong and Tanner (1996). At this point, we had a high degree of confidence that the model would represent patch sizes and shapes, as well as disturbance frequencies consistent with historical data for this land base.

LANDMINE was modified for this study to simulate various harvesting strategies. Five disturbance scenarios were simulated: the natural fire disturbance regime (Natural), and four harvesting regimes. The harvesting regimes included low, medium, and high biodiversity emphasis options from the biodiversity guidebook, as described in Table 1 . These are hereafter referred to as Low, Medium, and High disturbance scenarios respectively. The fifth simulation scenario was to 


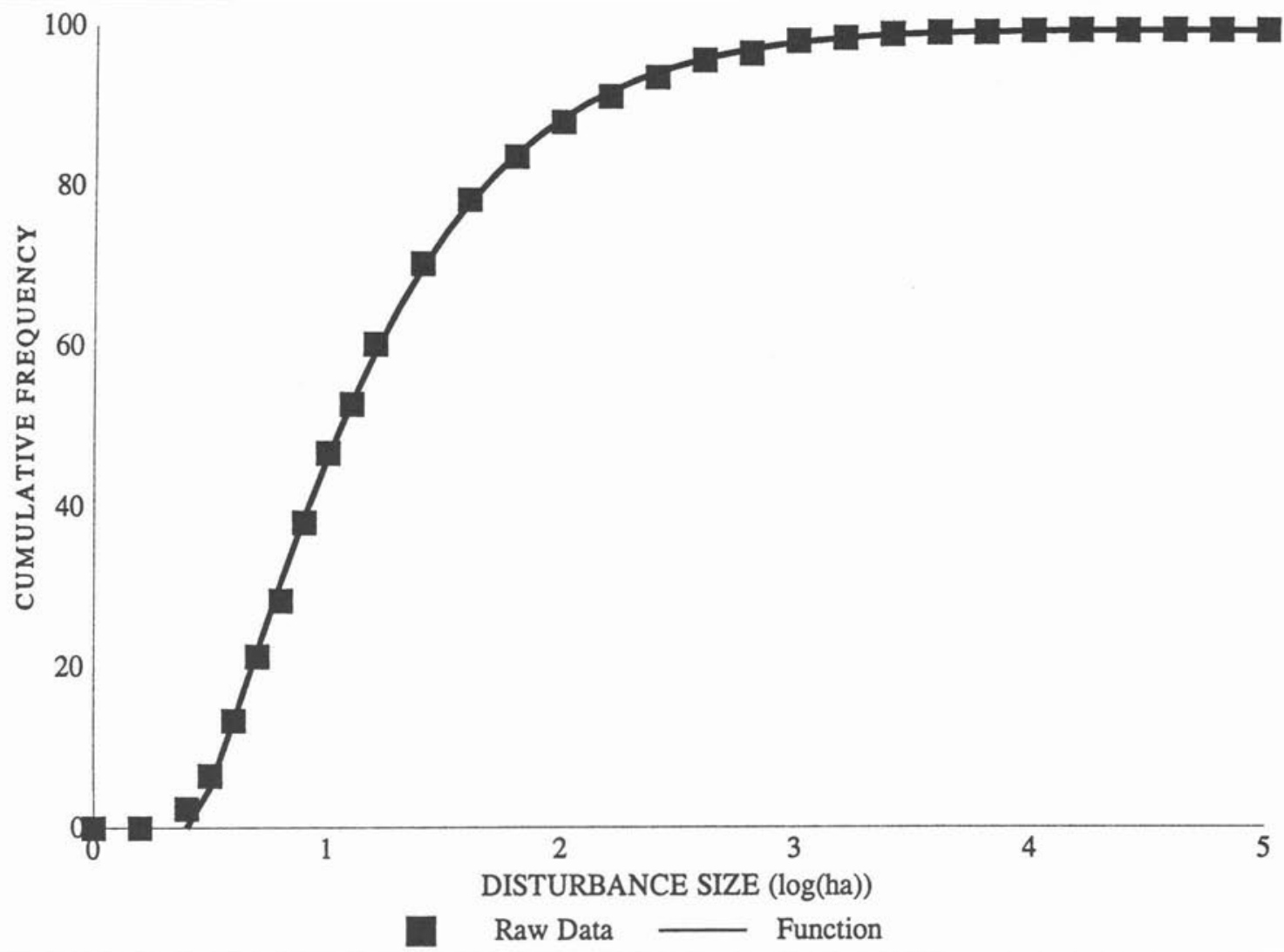

Fig. 1. Patch size raw data and function for the SMSmk1 landscape (from Andison 1996).

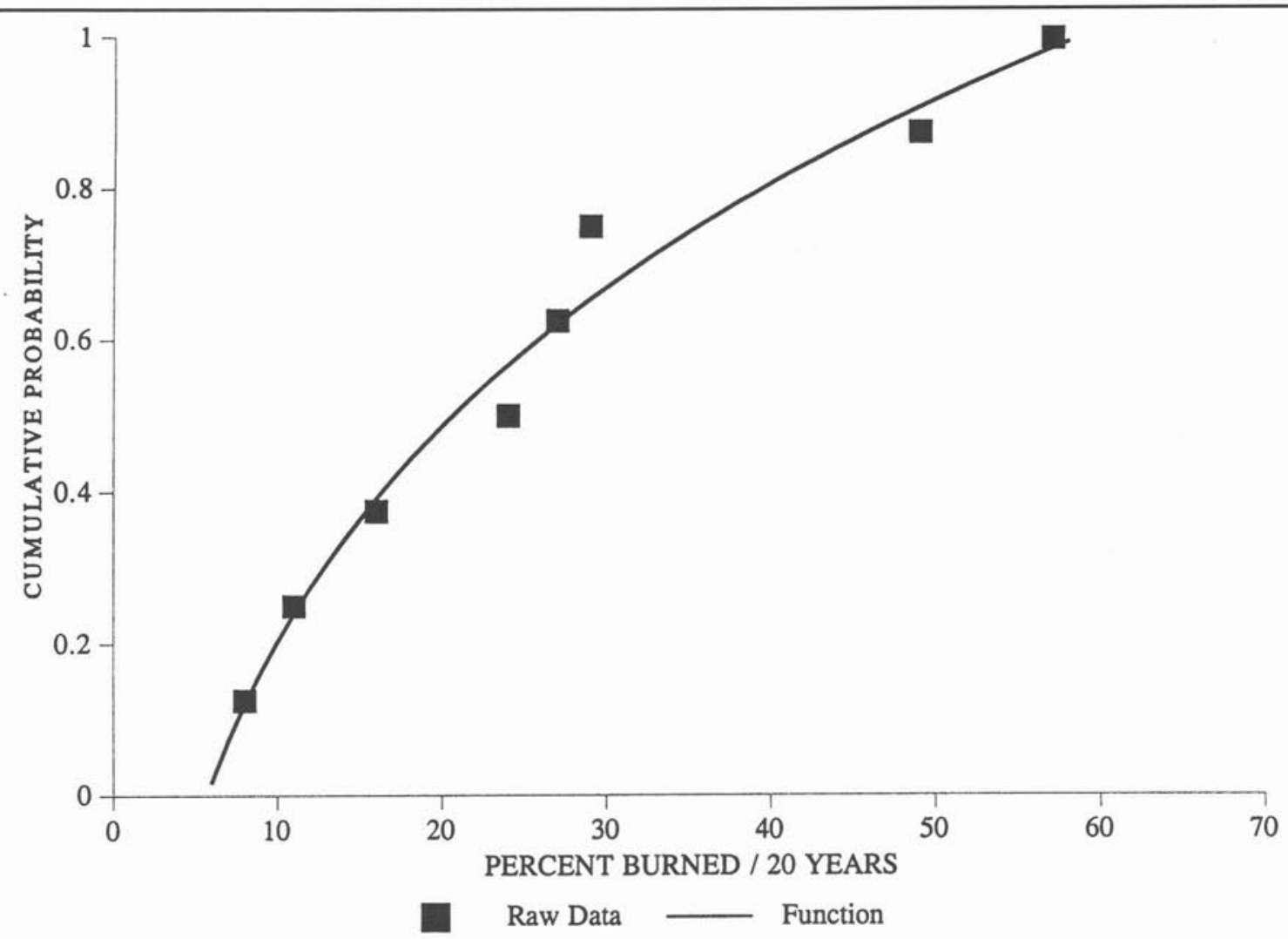

Fig. 2. Raw data and function for percent burned per 20-year period for the SBSmk1 landscape (from Andison 1996). 
Table 5. Area (ha) disturbed during the first four 20-year periods and the average over 25 periods for the Peculiar-Merton Landscape.

\begin{tabular}{lrrrrr}
\hline \multirow{2}{*}{$\begin{array}{l}\text { Time } \\
\text { (Years) }\end{array}$} & \multicolumn{5}{c}{ Disturbance Scenario } \\
\cline { 2 - 5 } & Natural & Low & Medium & High & 60 Ha \\
\hline 20 & 14712 & 33698 & 23121 & 12824 & 13816 \\
40 & 6288 & 14270 & 12552 & 12156 & 13186 \\
60 & 7452 & 7543 & 4101 & 6946 & 13186 \\
80 & 33895 & 4465 & 4283 & 4206 & 13186 \\
25 Period average & 22624 & 16369 & 13816 & 11584 & 13186 \\
\hline
\end{tabular}

(a)

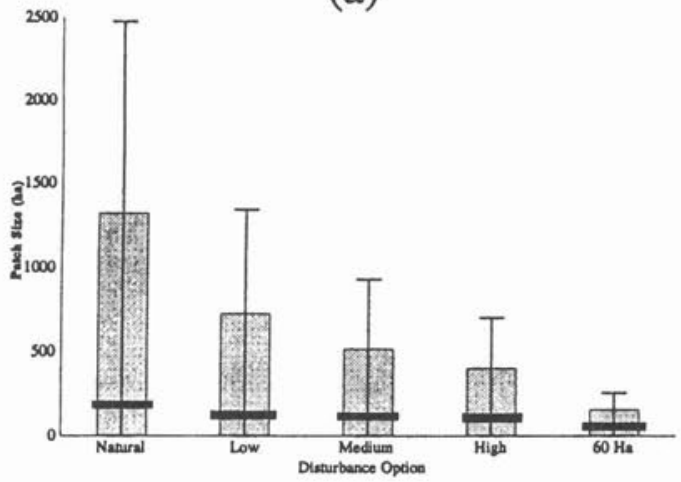

(c)

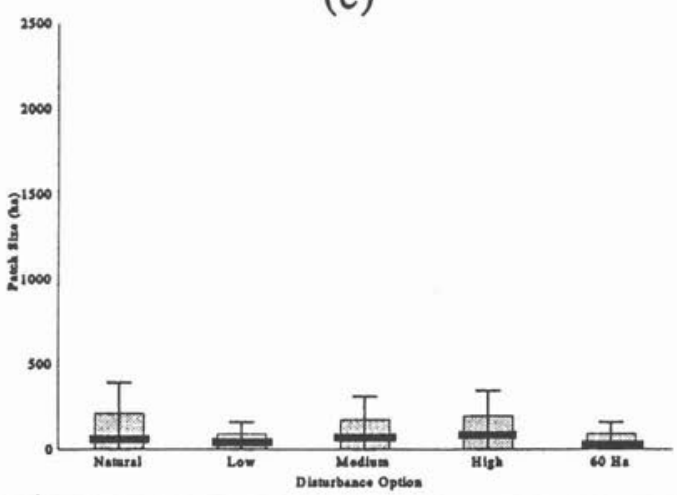

(b)

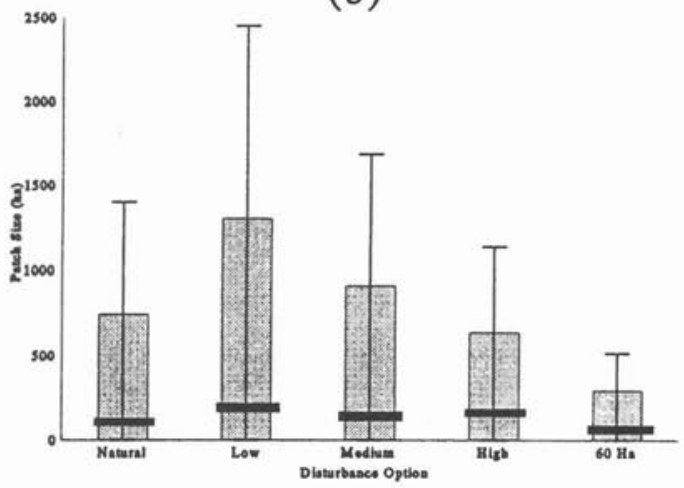

(d)

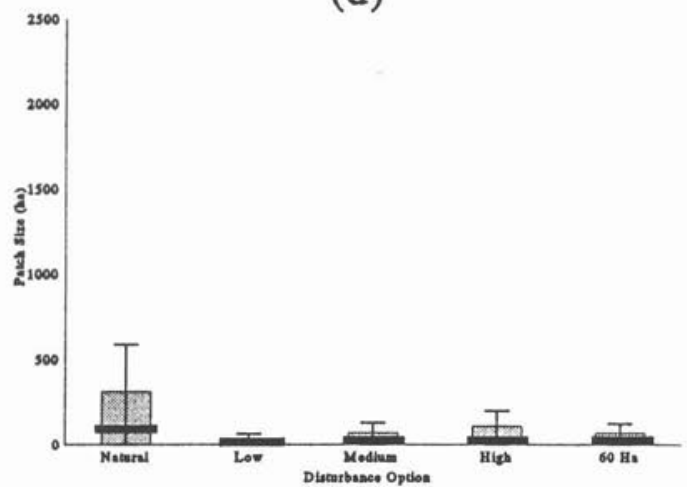

Fig. 3. Average (horizontal bar) $68 \%$ (vertical box) and $95 \%$ (vertical line) confidence intervals for patch size distribution for the early (s), pole (b), mature (c), and old (d) seral-stages for the Peculiar-Merton landscape from simulation.

represent the current cutting strategy, limiting cutblock sizes to $60 \mathrm{ha}$, and will be referred to as the $60 \mathrm{Ha}$ scenario. Each of the four harvesting regimes allowed for $350 \mathrm{~m}$ buffers around each disturbance (cutblock) for at least 20 years. The area to be disturbed for each harvesting option was calculated at the beginning of each 20-year period based on the rules outlined in the biodiversity guidebook, as well as any spatial or adjacency restrictions it imposes.

For each disturbance scenario, twenty-five 20-year runs were completed with a summary file created at the end of each 20 year period. Keep in mind that this does not project the landscape forward in time 500 years, but rather creates 25 different landscape snapshots. The difference being that the former pre-supposes constant climatic conditions, whereas the latter creates multiple landscape scene possibilities under constant burning conditions. Essentially, we just want to increase our sample size.

The summary file from the end of each 20-year time-step was analyzed using the FRAGSTATS spatial analysis pattern program (McGarigal and Marks 1994). Using landscape pattern metrics in anything other than a relative, comparative sense can be extremely misleading, and would require interpretations beyond the intended scope of this paper. For this reason, only the most basic, and most recognized spatial and non-spatial summaries are provided: disturbance frequency levels, patchsize distribution, forest edge density and amount of interior area, and seral stage representation. Disturbance frequency was determined as the average amount of area disturbed per 20-year period. The patch-size distribution was quantified using the average patch-size and its standard deviation. For this analysis, the 


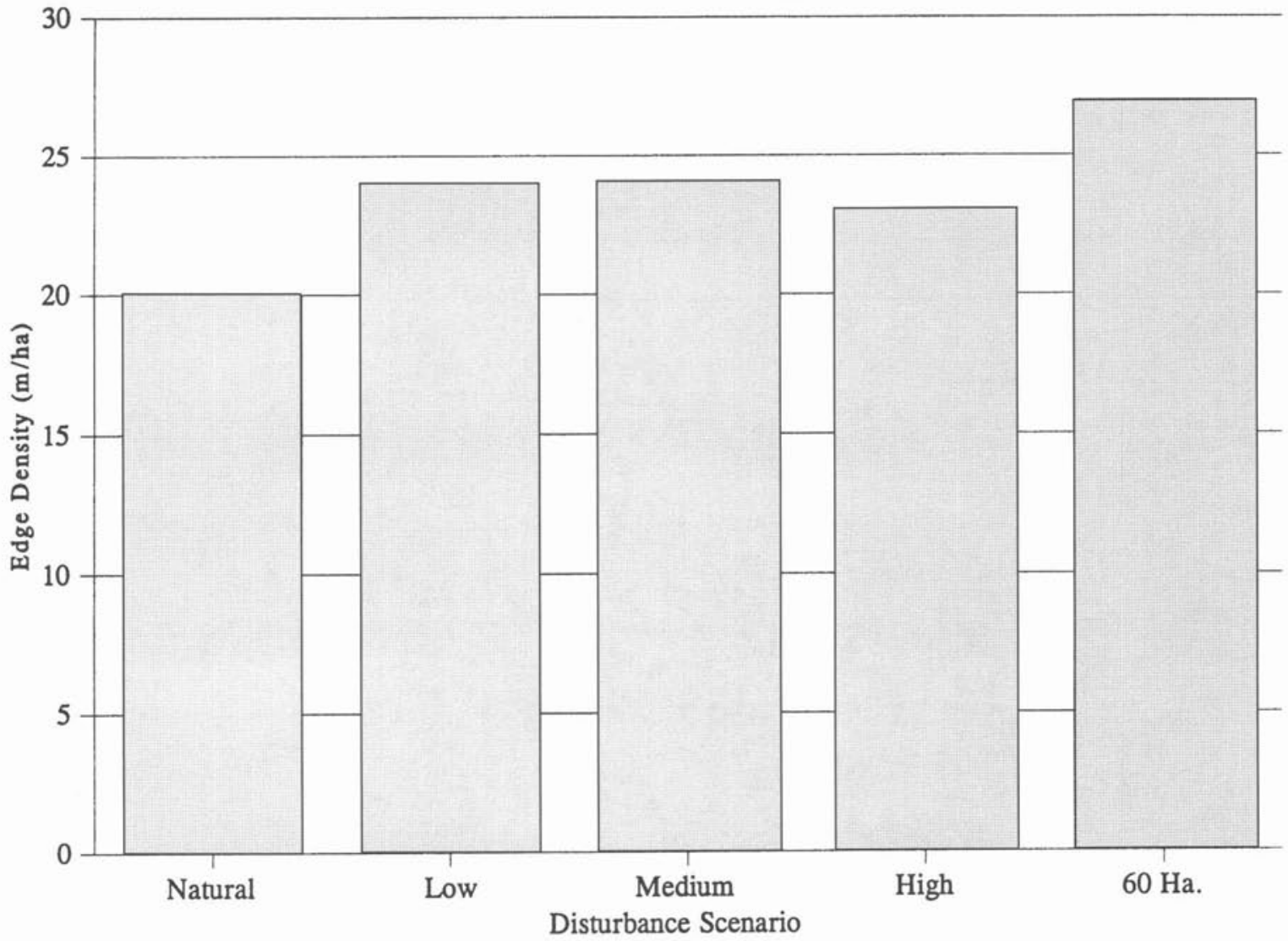

Fig. 4. Average edge density created by each disturbance scenario in simulation on the Peculiar-Merton landscape.

only edge recognized was that between a recent disturbance ( 0 to 20 years of age) and any other age of forest. Forest to nonforested edges were not included. Interior areas were defined as forest area further than $100 \mathrm{~m}$ from an edge. Seral stage representation was measured using the average percent of the forest area within a pre-defined age range and its standard deviation. Ages for the various seral stages were taken directly from the Biodiversity Guidebook (BC Ministry of Forests and BC Environment 1995 ): 0 - 39 years, $40-99$ years, $100-139$ years, and 140 years or greater.

\section{Results}

\section{Disturbance Frequencies}

The average area disturbed during each 20-year period ranged widely. By far the greatest frequency of disturbance occurred in the Natural scenario, averaging 22624 ha every 20 years (Table 5). The Natural scenario also created the highest variation in disturbance frequency. However, keep in mind that the figures for the Natural scenario given in Table 5 are merely the results of a particular set of stochastic simulation runs, they are not predictions. The highest level of disturbance among the management scenarios was the Low option (16369 hectares), and the lowest level from the High option (11 584 ha); almost half of that disturbed from the Natural scenario.

The differences in disturbed area among the management scenarios were most dramatic when compared over the short term. For instance, the Low scenario allowed harvesting of over one third of the forested land base over the first 20 years
(33 698 ha). The Medium scenario allowed depletion of 23121 hectares, and the High scenario only 12824 hectares in the first 20 years.

After the first 20 year period, the allowable harvestable area for the managed scenarios drops dramatically and also begins to converge. By the fourth 20 -year period, the allowable harvested area varied only from 4206 to 4465 ha between the High and Low options. After this point, the allowable harvested areas began to increase once again. This cyclical pattern of allowable harvestable area repeated for the length of the simulation. In other words, no steady flow of timber developed.

\section{Landscape Patch Size}

Average patch size has little or no meaning from a landscape pattern perspective since most patches are quite small. In this case, the averages did not vary tremendously (Fig. 3). However, patch size ranges did differ between treatments.

Younger patches had the greatest range of patch-sizes (Fig. 3). This is to be expected since patches are more likely to be broken up by more recent disturbances as they age, and the chances diminish of very large patches existing.

The Natural scenario showed the greatest variability of patchsizes overall, because it was the only scenario for which an artificial maximum disturbance size was not imposed. Between the managed scenarios, no single treatment showed wider ranges of patch sizes. For the youngest two seral stages, the range of patch-sizes was greatest for the Low scenario and least for the 


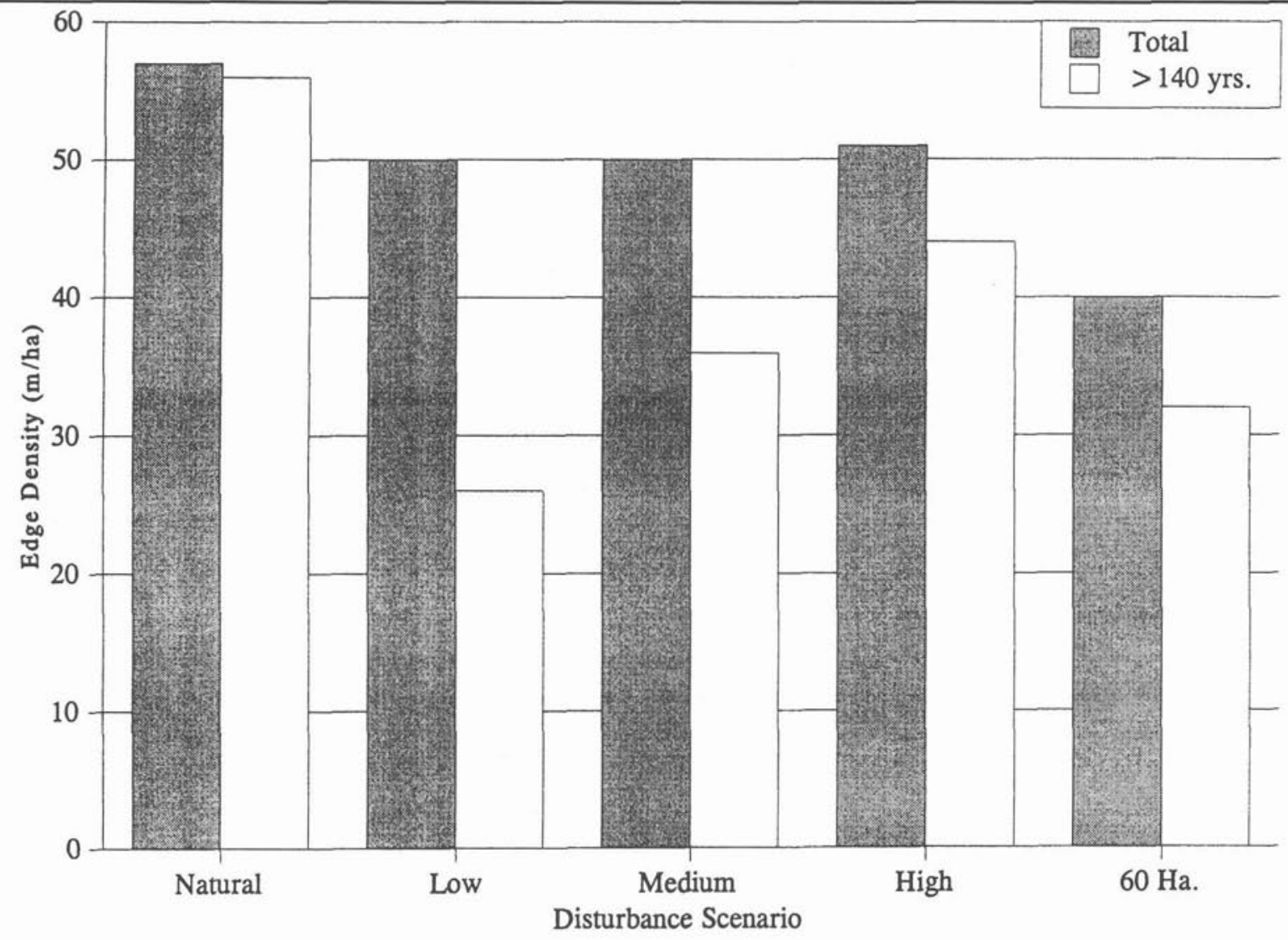

Fig. 5. Average interior areas in for all areas, and for areas $>140$ years, created by each disturbance scenario in simulation on the PeculiarMerton Landscape.

High scenario (Fig. 3a and 3b). For the mature and old seral stages, this trend was reversed, although the differences were smaller (Fig. 3c and 3d). In fact, one could argue that the choice of biodiversity option had little or no impact on the patch size range of older forest.

\section{Edge Density and Interior Area}

The Natural scenario created the lowest edge density $(20 \mathrm{~m} / \mathrm{ha})$ (Fig. 4) and the highest percentage of interior area $(57 \%)$ (Fig. 5). The 60 Ha scenario created the lowest percentage of interior area $(40 \%)$ and the highest edge density $(27 \mathrm{~m} / \mathrm{ha})$. Although these differences may not seem that great, consider that the difference between the average amount of interior forest for the two scenarios is over 16500 ha (17\% of 97176 ha).

The three biodiversity scenarios had much higher amounts of forest interior than the $60 \mathrm{Ha}$ scenario, but still had considerably less interior than the Natural scenario. Similarly, the edge densities for these three scenarios were about midway between that of the Natural scenario and the $60 \mathrm{Ha}$ option. There was little or no difference between the three biodiversity scenarios for either the edge density or interior forest.

In contrast to the results for the landscape as a whole, the interior area for forest older than 140 years differs considerably among the disturbance scenarios (Fig. 5). While the High scenario created interior area percentages close to those shown by the Natural scenario ( $44 \%$, respectively versus
$56 \%$ ), the Low scenario actually created less interior area than the $60 \mathrm{Ha}$ scenario ( $26 \%$ versus $32 \%$ respectively).

\section{Seral Stage Distribution}

The average area in the old seral stage under the Natural scenario $(18 \%)$ was closer to the Medium scenario (15\%) than any of the other management scenarios (Fig. 6). The High scenario created an average of $23 \%$, and the Low option produced only $11 \%$ old forest. The minimum amount of the old seral stage produced from the management scenarios all compared favourably to the targets. The mean percentages of the area, less two standard deviations in the "old" seral stage for the Low, Medium, and High scenarios were all close to the minimum recommended by the Biodiversity Guidebook (BC Ministry of Forests and BC Environment 1995) (Fig. 6).

A comparison of the ranges of the seral stage percentages reveals some large discrepancies. While the Natural scenario allowed as little as 3\% and as much as $33 \%$ old forest at any given time, each of the imposed management scenarios severely restricted this range (Fig. 6). The average change in percentage of "old" forest from one 20-year period to the next under the Natural scenario was $8 \%$. The average rate of change for managed scenarios ranged between $2 \%$ and $4 \%$.

A similar, but more dramatic pattern was found for "old+mature" (combined) areas greater than 100 years of age (Fig. 7). The Natural scenario allowed anywhere from $4 \%$ to $53 \%$ mature forest, averaging $29 \%$. Again, the Medium and 


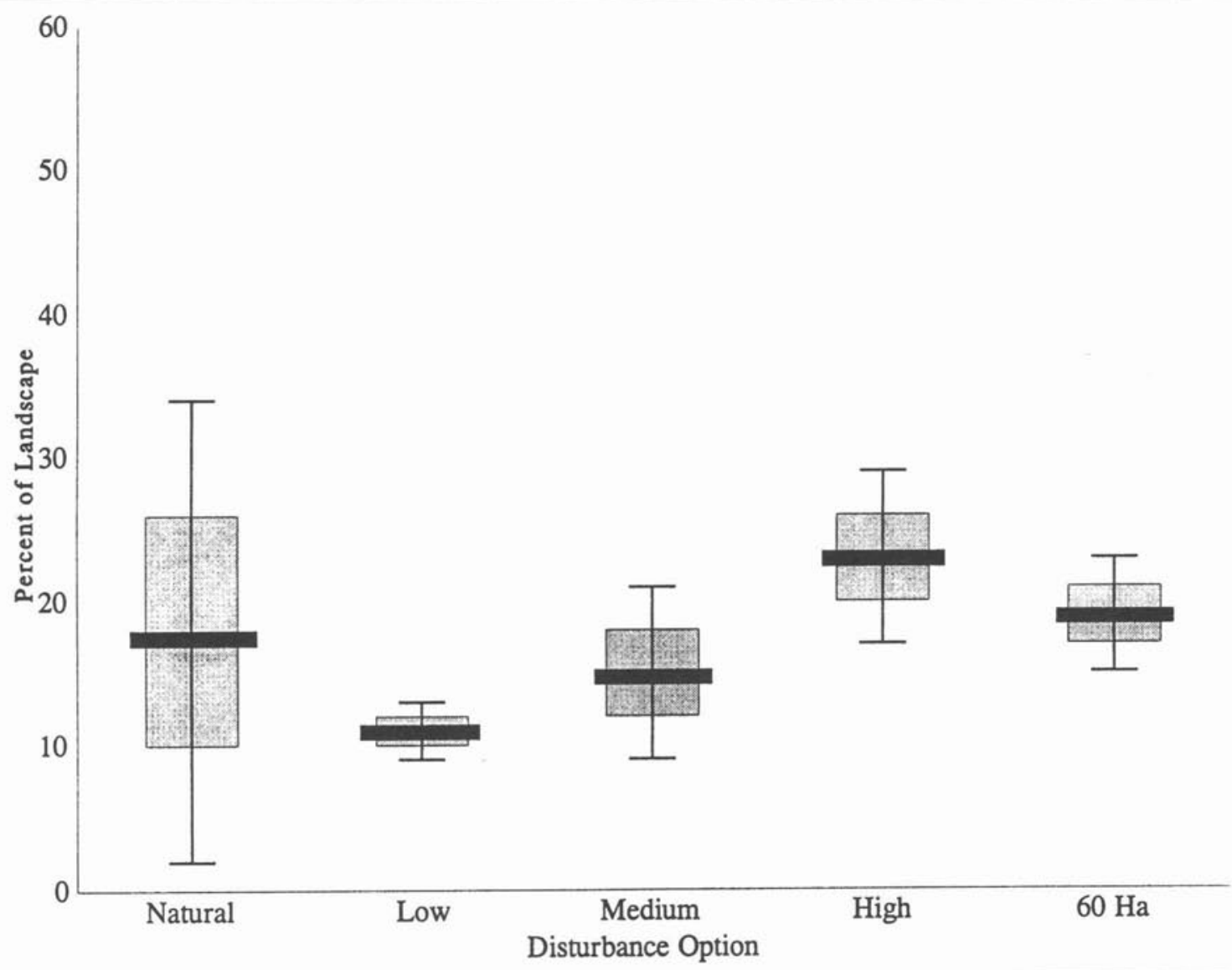

Fig. 6. Average (horizontal line), $68 \%$ (vertical box), and $95 \%$ (vertical line) confidence intervals for the amount of old seral-stage forest on the Peculiar-Merton landscape from simulation.

High scenarios both did a reasonable job of leaving appropriate percentages of mature forest on average, but none of the management scenarios came close to the range found with the Natural scenario (Fig. 7).

For the "young" seral stage, the Natural scenario again showed a wide range of areas present in young forest (Fig. 8); however, the Low scenario closely matched both the average and the range of the Natural scenario. Young forest in the Medium scenario ranged less than the low scenario, while the High scenario averaged $10 \%$ less area than the Natural scenario, and ranged only about half as much. The amount of young forest in the three biodiversity options all ranged wider than in the $60 \mathrm{Ha}$ scenario.

\section{Discussion}

Most of the pattern differences found between the natural and the four managed disturbance regimes can be attributed to a small number of factors: disturbance size limitations, greenup requirements, restricting disturbance rates, and the selectivity of harvesting operations.

The most obvious difference between the managed scenarios and the natural regime is the limitation of maximum disturbance sizes to 1000 hectares. This alone was largely responsible for the restricted interior forest area, increased edge density, and lower range of patch sizes across all seral stages of the managed scenarios compared to natural disturbance patterns. Disturbances on the SBSmk1 historically range well over
100000 hectares (Andison 1996). Furthermore, recall that none of the cutblocks in the four managed scenarios were allowed to get closer than $350 \mathrm{~m}$ to each other for 20 years. Shortening this time restriction to "green up" would have allowed a wider range of patch sizes, greater interior areas, and less edge to develop.

Limiting the range of disturbance rates limits the degree to which age-class distributions can vary relative to natural patterns. For instance, the simulation exercise demonstrated that landscapes of this size were just as likely to have virtually no old forest, as they were to have over $20 \%$ old forest. The guidelines allow no such latitude, and essentially fix the percentage of older forest to the minimum allowed.

Restricting harvesting operations to merchantable stands has several impacts. First, overall rates of disturbance are far less than expected under a natural disturbance regime since no pre-commercial or non-commercial areas are disturbed. This in turn affects patch size ranges as well. The Natural scenario created the largest range of patch sizes, in part because the very high and very low levels of disturbance it creates allowed the opportunity for large contiguous young patches to form. The managed treatment which permitted the smallest level and range of disturbance rates allowed less opportunity for very large contagious patches to form. Ironically, this happened to be the high biodiversity option.

The combination of the delineation of merchantable, commercial forest areas, together with the regulation of disturbance 


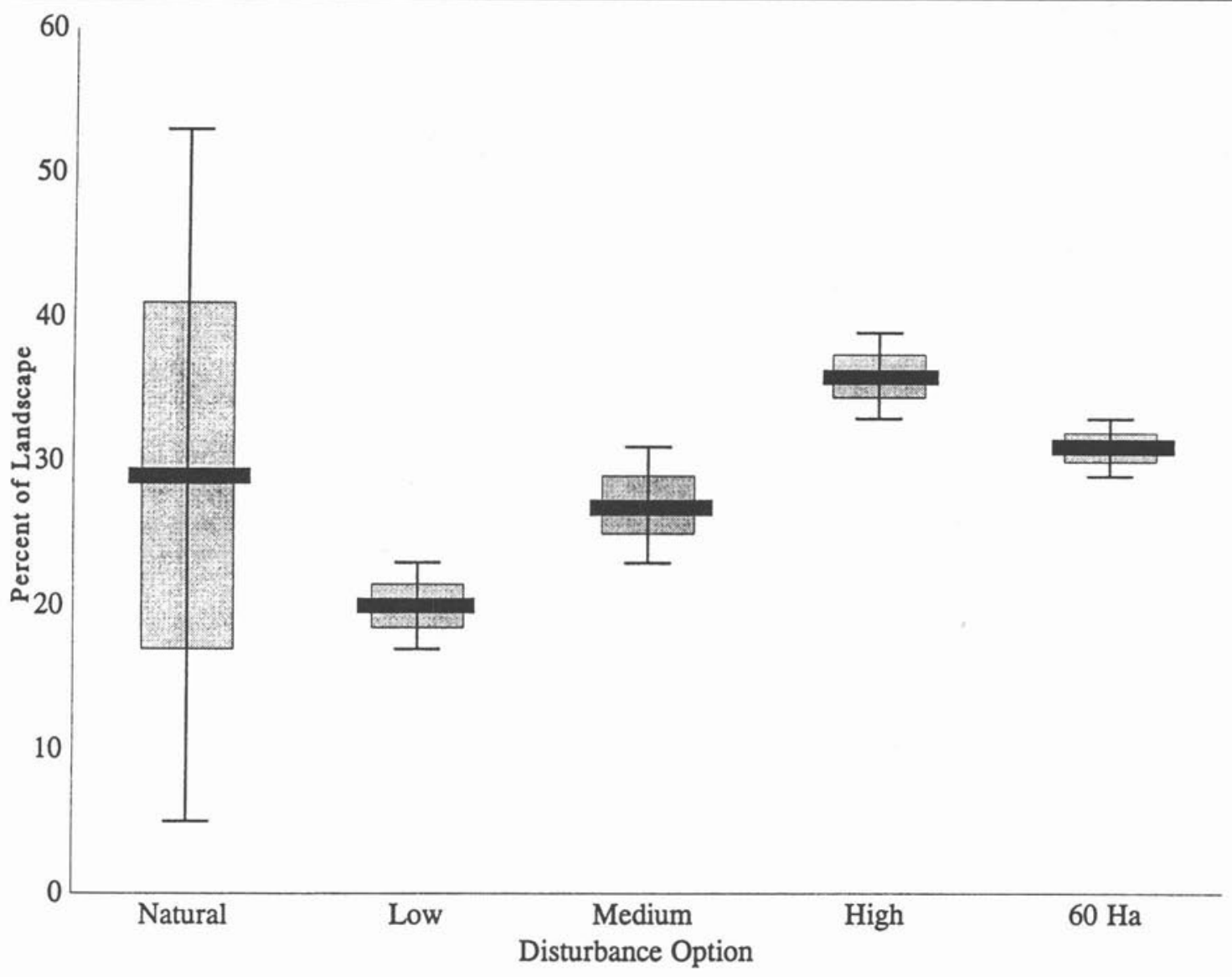

Fig. 7. Average (horizontal line), $68 \%$ (vertical box), and $95 \%$ (vertical line) confidence intervals for the amount of old+mature seral-stage forest on the Peculiar-Merton landscape from simulation.

rates had a dramatic impact on interior areas of old forest. For instance, note that the average amount of old forest from the natural scenario is comparable to the average amount created by most of the managed options. However, the percentage of old forest interior forest is generally far less than that found in the natural scenarios. This is partly due to the rules governing definitions of harvestable areas. The Prince George TSA document (BC Ministry of Forests 1995) states that areas of low productivity, or that are environmentally sensitive, inoperable, or having non-commercial species cannot be harvested, but are allowed when considering the allowable cut calculation. Such rules always result in permanent areas of old forest. According to Table 2, these permanent reductions account for $10 \%$ of the forest, virtually all of the minimums allowed under the low and medium biodiversity emphasis scenarios. Since there is no impetus to leave more than the minimum suggested in the guidelines, this percentage will vary little through time or space, as natural percentages would.

Leaving a constant percentage of old forest in non-merchantable areas has two negative impacts on the health of the entire landscape. First, these pieces of the landscape tend to be widespread and small, and thus do not create large percentages of interior forest. Second, it will only be a matter of time before these old areas become highly susceptible to both fire and mountain pine beetle (Dendroctonus ponderosae). Note that the high biodiversity option demands a minimum of $16 \%$ old forest
(Table 2) and thus created larger pieces of older forest with more interior area in the simulations.

\section{Conclusions}

This study tested, through simulation, the effectiveness of British Columbia's biodiversity guidelines in creating more "natural" landscape patterns. It deliberately used criteria beyond those mentioned in the document, and took a broader view of "naturalness" by comparing patterns resulting from various managed disturbance scenarios to those of a natural disturbance scenario. In the end, the success of the guidelines in achieving this goal depends on the criteria one uses.

On one hand, it could be argued that the specific strategies in the Biodiversity Guidebook achieve limited success. Against the pre-defined criteria, they create marginally more natural landscape patterns than the historical 60 hectare twopass harvesting regime. The various scenarios developed using these guidelines led to simulated landscapes which had larger and more variable patch sizes, greater overall interior forest area, and seral stage percentages within natural ranges compared to the $60 \mathrm{Ha}$ option.

On the other hand, the pattern differences between the Natural scenarios and those created using the guidebook recommendations were still quite significant. The guidelines fare even worse when judged using criteria beyond those specifically defined within the rules. For instance, the Low, 


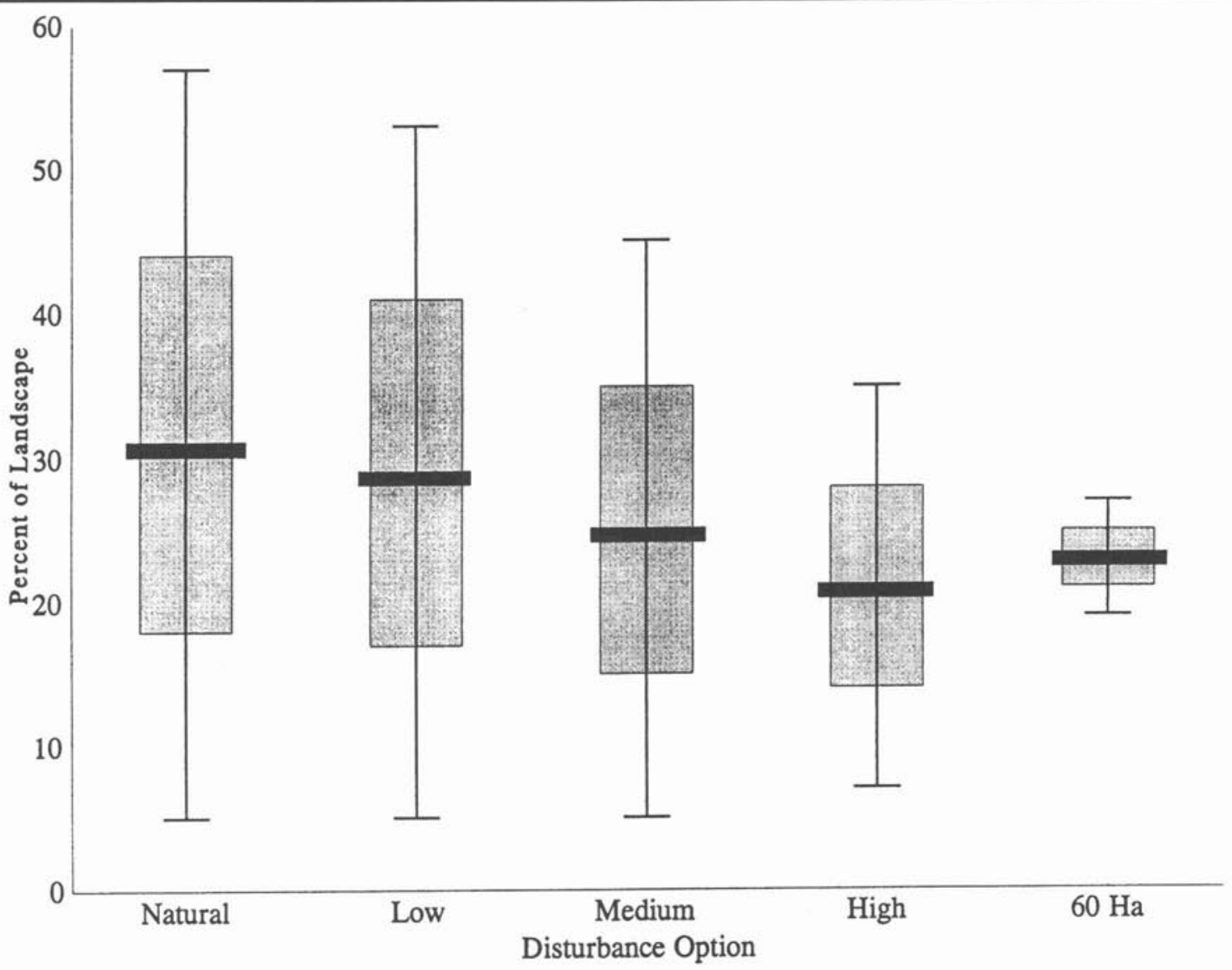

Fig. 8. Average (horizontal line), $68 \%$ (vertical box), and $95 \%$ (vertical line) confidence intervals for the amount of early seral-stage forest on the Peculiar-Merton landscape from simulation.

Medium, and High options of biodiversity imply a scale of increasing naturalness, yet the simulations showed this not to be the case. The High option created no more interior forest area or lower edge densities than either the Medium or Low option. The Low option was actually the most effective at creating natural patch-size ranges and proportions of young seral stage forest. The Low option also allowed disturbance rates closer to those found naturally.

For other natural attributes of this landscape the biodiversity options created no more natural patterns than did the 60 hectare two-pass system. For instance, the biodiversity guidelines do nothing to create more natural patterns of disturbance rates. In fact, the high biodiversity option only allows about half of the amount of disturbance found naturally on the SBSmk1. Similarly, patch sizes and interior areas of old and mature forest are no more natural than a two-pass strategy would create.

These findings should not be particularly surprising. The focus of the Guidelines is on patch-size distribution and maximum and minimum allowable seral stage proportions, not temporal variability or interior forest area controls. Nor is it all that surprising that the simulated landscape patterns resulting from the managed scenarios were different from those of the natural landscape. What was most revealing is the high degree to which this was true. Considering the results of this study as a whole, it could be argued that the Biodiversity Guidelines created a landscapes no less "fragmented" than a 60 hectare, 2-pass harvesting system would.
There are several reasons for this. First, there are certain, known, aspects of natural disturbance regimes that we as a society are not ready to accept. For instance, despite the fact that we know that fires well in excess of 1000 hectares commonly occur on this landscape, creating very large contiguous harvest blocks is unacceptable. There are also aspects of natural disturbance regimes that cannot be emulated for economic or practical reasons, such as the conservation of most of the biomass on disturbed sites, or leaving remnant islands within disturbances unharvested indefinitely. One of the main reasons that we are having trouble emulating natural disturbance is that we simply do not have sufficient knowledge. As this study well demonstrated, we have much to learn about the patterns that the processes of natural disturbance create. For instance, the landscape units designed for the Prince George Forest District are far too small to allow for a natural range of patterns, and thus fragmentation is an inevitable result regardless of harvest area size ranges.

In the end, no one, including $\mathrm{BC}$, should expect to be closely approximating natural patterns because we have yet to acquire sufficient ability and knowledge. However, we do have the desire, which raises an important question of how to reconcile the need to define landscape-level guidelines when significant knowledge gaps exist. Clearly, this study demonstrated the dangers of over-simplifying complex behaviour, not addressing appropriate scales, and imposing pre-conceived ideas of landscape patterns as rules. In other jurisdic- 
tions, such as Alberta and Saskatchewan, rather than drafting guidelines, the Provincial governments are allowing the tenure-holders to define and defend pattern interpretations.

The advantages and disadvantages of legislated methods will not be argued here. The point we are trying to make is that regardless of the ultimate manner in which natural patterns are integrated, the strategy should involve several key components. First and foremost, it must be based on comprehensive research of two types. The first type of research should focus on recognizing the patterns and understanding the processes of disturbance. As this paper well demonstrates, we have much to learn about natural disturbance. Furthermore, extrapolation of research from one area to another is not recommended since even simple metrics such as patch sizes and shapes tend to be unique to each landscape (Andison 1997). The second type of research necessary is the study of the ecological responses (of species, guilds, soil and water processes, etc.) to the natural patterns. This type of research will allow us to move beyond indiscriminate mimicry to a more informed level of natural pattern integration.

The distinction between pattern-oriented and responseoriented research, as discussed above, is important, and leads to the second component of a natural pattern program. Until proven otherwise by response-oriented research, we should consider all observed disturbance patterns to be equally relevant. In other words, in the absence of better information, we must assume that any and all natural patterns have an ecological purpose(s). For instance, we cannot dismiss the importance of remnant island spacing or structure on the basis of not having any evidence to prove it. Twenty years ago we would have used the same argument against very large cutblocks or coarse woody debris. Using natural patterns in the absence of complete knowledge is one of the bases of the concept of using natural patterns as management templates. Otherwise, we are imposing pre-conceived ideas of nature, the spirit of ecosystem-based management is compromised, and we revert to culturally-based forest management practices.

The final component for a successful natural pattern strategy is that it should be dynamic and allow for the consideration of new information. Some would refer to this as "adaptive," although it is really only making the highest and best use of available research and technology. For instance, the simulation exercise completed for this study demonstrates how spatial simulation modeling can be a valuable means of comparing and contrasting probable long-term pattern outcomes of management scenarios. Similarly, the discussion suggests some alternative strategies for achieving more natural patterns in the SBSmk 1 that were not previously considered: disturbing pre-commercial stands, combining several landscape units for long-term planning, shortening "green-up" requirements of adjacent cutblocks, better spatial management of large blocks of old forest, and even developing pro-active policies of dealing with natural disturbance events. It is noteworthy that the $\mathrm{BC}$ guidelines do not discuss possible integration with natural disturbance, yet there are limits to the degree to which fire, insects, disease and wind, can be controlled or predicted.

The problems of moving into ecosystem-based management extend far beyond BC. Moreover, it is a secondary matter whether or not the vehicle for implementing natural pattern emulation within ecosystem management is a guidebook. Given our limited understanding and ability, it is more important that that vehicle include the components discussed above, openly acknowledge the current limitations as we know them, and develop a formal means of progressing as we gain the required information. At the moment, aside from a "living document" reference, the $\mathrm{BC}$ biodiversity guidelines include none of these mechanisms formally. This fact is more of an issue than the apparent failure of the guidelines to better emulate natural patterns.

\section{Acknowledgements}

The project described in this paper was initiated and sponsored by the Prince George Forest District of the British Columbia Ministry of Forests. The model employed was developed as part of the senior author's Ph.D. research at the University of British Columbia. This research was supported financially by the British Columbia Ministry of Forests, and supported intellectually by a large number of individuals including Craig DeLong, Dale Siep, and Geoff Burrows. This support is gratefully acknowledged. We would also like to thank two anonymous reviewers for their valuable comments.

\section{References}

Andison, D.W. 1996. Managing for landscape patterns on the SubBoreal forest of British Columbia. Ph.D. Dissertation, University of British Columbia, Vancouver, BC. 197 p.

Andison, D.W. 1997. Landscape fire behaviour patterns in the Foothills Model Forest. Prepared for the Foothills Model Forest, Hinton, Alberta. 63 p.

Baker, W.L., S.L. Egbert and G.F. Frazier. 1991. A spatial model for studying the effects of climatic change on the structure of landscapes subject to large disturbances. Can. J. For. Res. 19: 700-706. BC Ministry of Forests. 1995. Prince George TSA Timber Supply Analysis. BC Ministry of Forests, Victoria, BC. 79 p.

BC Ministry of Forests and BC Environment. 1995. Forest Practices Code of British Columbia Biodiversity Guidebook. BC Ministry of Forests, Victoria, BC. 99 p.

Clarke, D.C., J.A. Brass and P.J. Riggan. 1994. A cellular automaton model of wildfire propagation and extinction. Photo. Eng. \& Remote Sensing. 60(1): 1355-1367.

DeLong, C. and D. Tanner. 1996. Managing the pattern of forest harvest: Lessons from wildfire. Biodiversity and Conservation 5:1191-1205.

DeLong, C., D. Tanner and M.J. Jull. 1993. A field guide for site identification and interpretation for the southwest portion of the Prince George forest region. BC Ministry of Forests, Victoria, BC. 290 p. Johnson, E.A. 1992. Fire and vegetation dynamics: Studies from the North American Boreal Forest. Cambridge U. Press, Great Britain. $129 \mathrm{p}$.

McGarigal, K. and B.J. Marks. 1994. FRAGSTATS - Spatial pattern analysis program for quantifying landscape structure. V. 2.0. Oregon State U., Corvallis OR.

Mladenoff, D.J., G.E. Host, J. Boeder and T.R. Crow. 1993. LANDIS: A spatial model of forest landscape disturbance, succession, and management. In Second International Conference on Integrating Modeling and GIS. NCGIA, Santa Barbara, California.

Parminter, J. 1983. Fire-ecological relationships for the biogeoclimatic zones of the Cassiar timber supply area: Summary report. In: BC Ministry of Forests, Northern Fire Ecology Project: Cassiar Timber Supply Area. Internal report. 64 p.

Payette, S. 1993. Fire as a controlling process in North American boreal forest. In D.C. West, H.H. Shugart and D.B. Botkin (eds.). Forest Succession: Concepts and Applications. pp.144-169. SpringerVerlag, New York.

Taylor, S.W. and R.G. Pike. 1995. Field guide to the Canadian Forest Fire Prediction (FBP) System. Pacific Forestry Centre, CFS, Victoria, BC. 